\title{
A eficácia do roteiro de autoestudo como recurso didático no ensino remoto
}

\author{
The effectiveness of the self-study script as a didactic resource in remote teaching \\ La efectividad del guion de autoestudio como recurso didáctico en la enseñanza remota
}

Recebido: 21/09/2021 | Revisado: 30/09/2021 | Aceito: 05/10/2021 | Publicado: 09/10/2021

\author{
Antonio Lemes Guerra Junior \\ ORCID: https://orcid.org/0000-0002-8771-908X \\ Universidade Estadual do Paraná, Brasil \\ E-mail: alguerrajunior@gmail.com \\ Juliana Fogaça Sanches Simm \\ ORCID: https://orcid.org/0000-0001-6328-0976 \\ Universidade Pitágoras Unopar, Brasil \\ E-mail: julianafogacasanches@gmail.com \\ Ednéia de Cássia Santos Pinho \\ ORCID: https://orcid.org/0000-0003-0008-5254 \\ Universidade Estadual de Londrina, Brasil \\ E-mail: ediuel@yahoo.com.br \\ Eliza Adriana Sheuer Nantes \\ ORCID: https://orcid.org/0000-0003-3260-7264 \\ Universidade Pitágoras Unopar, Brasil \\ E-mail: eliza@unopar.br
}

\begin{abstract}
Resumo
Para além de uma modalidade emergencial, o ensino remoto configura a efetivação de muitas e novas práticas pedagógicas que, antes, permaneciam à margem dos espaços educacionais - por falta de recursos ou, inclusive, por resistência. No contexto universitário público, essa dinâmica colocou professores e alunos em contato com novas relações de ensino e aprendizagem, mediadas sobretudo por tecnologias móveis digitais. Considerando esse contexto, este artigo baseia-se no objetivo de discutir a eficácia do "roteiro de autoestudo" como um recurso didático no âmbito do ensino remoto. Por meio de um estudo de caso, o texto descreve uma proposta de trabalho implementada por um dos autores deste trabalho, docente de um Curso de Letras, de modo a explorar os aspectos que sustentam sua prática pedagógica. As análises, à luz dos pressupostos teórico-metodológicos da área de ensino e tecnologia, contemplam a estrutura do roteiro adotada pelo professor, bem como as percepções dos estudantes que têm feito uso desse material em sua trajetória acadêmica. Os resultados apontam, em síntese, para o estabelecimento do roteiro de autoestudo como uma prática eficaz, que, no ensino remoto, permite ao aluno um diálogo mais próximo com o professor e, ao mesmo tempo, com o conteúdo.
\end{abstract}

Palavras-chave: Ensino remoto; Roteiro; Autoestudo.

\begin{abstract}
In addition to being an emergency modality, remote teaching configures the realization of many and new pedagogical practices that, before, remained outside educational spaces - due to lack of resources or, even, due to resistance. In the public university context, this dynamic brought teachers and students into contact with new teaching and learning relationships, mediated specially by digital mobile technologies. Considering this context, this article is based on the objective of discussing the effectiveness of the "self-study script" as a didactic resource under the scope of remote teaching. Through a case study, the text describes a proposal implemented by one of the authors of this work, professor of a Language Course, in order to explore the aspects that support his pedagogical practice. The analyses, based on theoretical-methodological assumptions in the area of teaching and technology, contemplate the structure of the script adopted by the teacher, as well as the perceptions of students who have made use of this material in their academic trajectory. In summary, the results point to the establishment of the self-study script as an effective practice, which, in remote teaching, allows the student to have a closer dialogue with the teacher and, at the same time, with the content.
\end{abstract}

Keywords: Remote teaching; Guide; Self-study.

\section{Resumen}

Además de ser una modalidad de emergencia, la enseñanza remota configura la realización de muchas nuevas prácticas pedagógicas que, antes, quedaban fuera de los espacios educativos - por falta de recursos o, incluso, por resistencias. En el contexto de la universidad pública, esta dinámica puso en contacto a profesores y estudiantes con nuevas relaciones de enseñanza y aprendizaje, mediadas sobre todo por las tecnologías móviles digitales. Teniendo en 
cuenta este contexto, este artículo se basa en el objetivo de discutir la efectividad del "guión de autoestudio" como recurso didáctico en el campo de la ensenãnza remota. A través de un estudio de caso, el texto describe una propuesta de trabajo implementada por uno de los autores de este trabajo, profesor de un Curso de Idiomas, con el fin de explorar los aspectos que sustentan su práctica pedagógica. Los análisis, a la luz de supuestos teórico-metodológicos en el área de la docencia y la tecnología, contemplan la estructura del guión adoptado por el docente, así como las percepciones de los estudiantes que han hecho uso de este material en su trayectoria académica. En resumen, los resultados apuntan al establecimiento del guión de autoestudio como una práctica efectiva, que, en la ensenãnza remota, permite al alumno tener un diálogo más cercano con el docente y, al mismo tiempo, con el contenido.

Palabras-clave: Ensenãnza remota; Guión; Autoestudio.

\section{Introdução}

Ser professor, independentemente do contexto em que se dá essa atividade, demanda uma série de conhecimentos, os quais se espraiam por diferentes dimensões, muito além de um fechado conjunto de teorias. Conforme Tardif (2014, p. 36), por exemplo, o saber docente é "um saber plural, formado pelo amálgama, mais ou menos coerente, de saberes oriundos da formação profissional e de saberes disciplinares, curriculares e experienciais".

Os três primeiros conjuntos desses saberes - da formação profissional, disciplinares e curriculares - correspondem, respectivamente, na perspectiva de Tardif (2014), aos conhecimentos pedagógicos adquiridos nas instituições de formação de professores, isto é, aqueles que fundamentam, basilarmente, a área da educação; os conhecimentos atrelados aos diferentes campos de conhecimento, ou seja, que originam as disciplinas pelas quais os professores são responsáveis; e os conhecimentos de ordem normativa ou procedimental, por assim dizer, vinculados à constituição de discursos, objetivos, conteúdos e métodos.

É, porém, nos saberes experienciais que essas reflexões introdutórias se concentram. Segundo Tardif (2014, p. 38-39), “[...] os próprios professores, no exercício de suas funções e na prática de sua profissão, desenvolvem saberes específicos, baseados em seu trabalho cotidiano e no conhecimento de seu meio". Nesse sentido, tais saberes "[...] brotam da experiência e são por ela validados. Eles incorporam-se à experiência individual e coletiva sob a forma de habitus e de habilidades, de saberfazer e de saber-ser. Podemos chamá-los de saberes experienciais ou práticos”.

Ainda conforme o autor, trata-se de um "[...] conjunto de saberes atualizados, adquiridos e necessários no âmbito da prática da profissão docente e que não provêm das instituições de formação nem dos currículos". Todavia, tais saberes “[...] não se encontram sistematizados em doutrinas ou teorias. São saberes práticos (e não da prática: eles não se superpõem à prática para melhor conhecê-la, mas se integram a ela e dela são partes constituintes enquanto prática docente) e formam um conjunto de representações", que se fazem presentes na arquitetura escolar, "a partir das quais os professores interpretam, compreendem e orientam sua profissão e sua prática cotidiana em todas as suas dimensões. Eles constituem, por assim dizer, a cultura docente em ação" (Tardif, 2014, p. 48-49).

Podemos considerar esses saberes, então, como aqueles que emergem da complexidade do contexto de atuação docente, sob influência de fatores como o ambiente escolar/acadêmico em que o docente está inserido (escola ou universidade, por exemplo), as relações dele com seus alunos e, também, com seus pares, ou ainda, numa dimensão que extrapola os limites do seu espaço profissional, os condicionantes socio-histórico-culturais, capazes de interferir diretamente, a depender de sua natureza, no desenvolvimento de práticas pedagógicas.

O cenário que vem se desenhando no decorrer dos últimos meses, por exemplo, em virtude do impacto da pandemia sobre as instituições escolares/acadêmicas, evidencia-se como uma fonte desses saberes experienciais, na medida em que professores, ao lado de saberes de formação, disciplinares e curriculares, têm desenvolvido novos conhecimentos, instaurando práticas, processos e instrumentos de intervenção didática, tomados como evidências da não estaticidade do fazer docente.

Considerando tais princípios norteadores, o objetivo deste texto reside em discutir a eficácia do "roteiro de autoestudo" como um recurso didático no âmbito do ensino remoto. Para seu alcance, recorremos metodologicamente a um 
estudo de caso, com a descrição de uma proposta de trabalho implementada na condução de algumas disciplinas de um Curso de Letras em uma universidade pública, espaço de atuação de um dos autores do trabalho.

Partindo dessa contextualização preliminar, na sequência, apresentamos: a fundamentação teórica que sustenta a discussão proposta pelo texto, incluindo as inter-relações entre ensino e tecnologia; os procedimentos metodológicos adotados no processo de exploração dos dados; e, por fim, a compilação dos principais resultados alcançados com as análises, tanto da estrutura do roteiro adotada pelo professor quanto das percepções dos estudantes que têm feito uso desse material em sua trajetória acadêmica, numa discussão que sustenta, também, as conclusões que encerram o trabalho.

\section{Referencial Teórico}

A partir da temática que delineia o trabalho ora apresentado, há a necessidade de uma fundamentação teórica sustentada em três pilares essenciais: (i) a caracterização da modalidade de ensino remoto, considerando sua natureza e sua essência multimodal; (ii) a diversidade de recursos passíveis de aplicação no processo de comunicação didática, ou seja, na atuação docente; e, a partir desse amplo conjunto de materiais, (iii) a delimitação do funcionamento teórico-metodológico do gênero "roteiro" nas práticas de ensino.

\subsection{A dinâmica multimodal do ensino remoto}

A pandemia da Covid-19 afetou substancialmente todas as esferas da sociedade, acarretando mudanças, sobretudo, nos modos de interação em razão da necessidade de distanciamento social. Com isso, uma das áreas mais acometidas foi, com certeza, a de ensino, tendo em vista a inviabilidade de as aulas acontecerem de forma presencial devido ao risco de contágio entre os envolvidos. As instituições educacionais precisaram se reinventar e, a partir dessa situação, a modalidade do Ensino Remoto Emergencial (ERE) ${ }^{1}$, pouco conhecida até então, tornou-se uma realidade em boa parte das escolas e universidades por todo o Brasil. E essa nova e obrigatória realidade, segundo Carneiro et al. (2020, p. 3), "lança as bases para fortalecer a aprendizagem mediada por tecnologias".

Quanto a isso, Carvalho (2020) aponta que, em pouco tempo, as instituições escolares, as quais, em sua grande maioria, utilizavam recursos digitais apenas com um caráter complementar às aulas presenciais, aproximando-se do que é chamado de ensino híbrido, "viram-se na emergência de levar suas salas de aula presenciais para o ambiente virtual" (Carvalho, 2020, p. 196). Em virtude disso, "o lento processo de incorporação das tecnologias digitais foi, subitamente, acelerado" (Carvalho, 2020, p. 197).

Porém, obviamente, pela urgência da situação, pelo menos nos primeiros meses, essa nova forma de ensinar, o ERE, instaurou-se sem um planejamento adequado e, principalmente, sem o devido preparo de boa parte dos envolvidos, ou seja, o trajeto foi sendo construído ao longo da caminhada.

Nesse sentido, superada a necessidade inicial de se estabelecer uma modalidade de emergência para a continuidade das práticas escolares e tendo em vista que tal práxis se estenderia por mais tempo do que o esperado, as instituições e os profissionais da educação passaram a traçar planos mais consistentes e organizados, em relação aos modos de ensino. Com isso, os recursos ofertados pelas instituições, públicas e/ou privadas, passaram a ser mais bem explorados, e o que antes era apenas teoria ou de uso esporádico para alguns passou a ser uma constante na prática de muitos: a multimodalidade, desse modo, passa a ser uma constante nas aulas dos mais variados níveis de ensino.

\footnotetext{
${ }^{1}$ Para Carvalho e Araújo (2020), o ERE diz respeito a um conjunto de atividades emergenciais que as escolas planejaram e executaram por meio de ferramentas virtuais ou outros meios disponíveis, visando minimizar os impactos da suspensão das aulas presenciais.
} 
Quando versamos sobre a esfera escolar, termos como "multimodalidade" e "letramentos" imbricam-se nas ações didático-pedagógicas, tendo em vista que elas são permeadas por escolhas e são influenciadas, também, pelo nosso conhecimento teórico-prático sobre os letramentos e os multiletramentos.

Nesse sentido, sobre as concepções do termo "letramentos", recorrermos aos estudos de Street (2014), visto que, segundo o pesquisador, estes são múltiplos e estão inseridos em contextos sociais variantes, pois as comunidades apresentam essa variação. Acrescente-se a isso que os letramentos sofrem influência de fatores socioculturais, temporais e das relações de poder que ocorrem na sociedade.

No que tange aos termos "multimodalidade" e "multimodal", os estudos sobre Semiótica Social são considerados o ponto de partida, sendo Kress e Van Leeuwen (1996) os precursores a destacar que a construção dos sentidos emerge do uso de palavra e imagem, logo temos mais de um código semiótico.

Quanto a isso, sabe-se que, há tempos, estudiosos como Dionísio (2011) e Rojo (2012) têm defendido a necessidade de apropriação de novas capacidades e práticas de compreensão dos conteúdos, uma vez que, na contemporaneidade, o texto não se reduz apenas ao impresso.

De acordo com Ribeiro (2020), escolhemos e mobilizamos recursos para dizer e mostrar o que queremos, e nosso poder semiótico e social reside nisso. Nesse sentido, novas formas de produção e, consequentemente, de leitura têm sido cada vez mais frequentes nas variadas esferas sociais. Nelas, agregam-se às palavras outros recursos, tais como fotos, gráficos, infográficos, vídeos e sons, formando, assim, os chamados textos multimodais, como propagandas, vídeos, notícias na TV e na internet, animes, cartuns, memes, gifs, entre muitos outros.

Rojo (2012, p. 13) destaca que a adoção do termo "multiletramentos” veio para abarcar aspectos que já estão presentes na sociedade, um deles ligado à cultura, e o outro aos textos: "a multiplicidade cultural das populações e a multiplicidade semiótica de constituição dos textos por meio dos quais ela se informa e se comunica".

Dionísio e Vasconcelos (2013, p. 20-21) asseveram que, na linguagem, há influência dos suportes dos textos, “onde os modos (imagens, escrita, som, música, linhas, cores, tamanhos, ângulos, entonação, ritmos, efeitos visuais, melodias, etc.) são realizados". Assim, chega-se à noção de "recursos semióticos", um "termo que tem sido utilizado para descrever esses modos e como eles se integram através das modalidades sensoriais (visual, auditiva, olfativa etc.) na construção de eventos e textos multimodais".

Bacich (2018, p. 144) destaca que, para haver uma mudança na cultura escolar, aspectos como “[...] a valorização e a construção da autonomia do aluno, a organização do espaço escolar para o uso integrado das tecnologias digitais, a reflexão sobre qual a melhor forma de avaliar nesse processo", dentre outras questões, são temas essenciais que devem ser contemplados, de forma articulada, dentro da gestão escolar, “[...] com o objetivo de refletir sobre a importância de colocar o estudante e as relações pedagógicas no centro do processo".

Tais proposições já haviam sido justificadas em virtude de terem surgido novas demandas no século XXI que nos trouxeram a necessidade do desenvolvimento de competências necessárias em um mundo interconectado, dentro de uma sociedade que requer "criatividade e inovação, pensamento crítico e capacidade de resolução de problemas, colaboração e trabalho em equipe", indo além, pois se trata de termos - ou desenvolvermos - maior "autonomia e flexibilidade", assumindo a concepção de que o ato de aprender passa a ser permanente (Dudeney, Hockly, \& Pegrum, 2016, p. 17).

Dudeney, Hockly e Pegrum (2016, p. 17) definem letramentos digitais como "habilidades individuais e sociais necessárias para interpretar, administrar, compartilhar e criar sentido eficazmente no âmbito crescente de comunicação digital".

Em estudo anterior, Buckinghan (2010, p. 49) já pontuava que o letramento digital vai além da exploração funcional de se manusear computadores ou mesmo usá-los para a realização de pesquisas. É imprescindível o desenvolvimento de habilidades como saber selecionar e localizar materiais disponíveis na rede, via hiperlinks e outros, assim "não basta apenas ter 
habilidades necessárias para recuperar informações na mídia digital, é preciso ser capaz de avaliar e usar a informação de forma crítica se quiser transformá-la em conhecimento".

Mediante o exposto, diante do contexto educacional disruptivo que ora vivenciamos, o ERE, o docente precisa mobilizar diferentes recursos e linguagens, a fim de estabelecer a comunicação didática. Por isso, após recorrermos aos estudos de Kress e Van Leeuwen (1996), Rojo (2012), Dionísio e Vasconcelos (2013), Street (2014), Dudeney, Hockly e Pegrum (2016) e Bachich (2018), apresentamos nossa concepção dos multiletramentos no contexto atual, defendendo que eles requerem que o professor assume que: (i) os textos vão além dos aspectos verbais, pois estão inseridos em contextos sóciohistóricos-culturais; (ii) as imagens têm sentidos que ultrapassam meras ilustrações; (iii) os significados são construídos a partir de um conjunto de signos; (iv) na construção dos significados, deve-se considerar as pluri e multiformas de ressignificação, visto que elas emergem de contextos plurilinguísticos e multiculturais; (v) na análise dos textos, devem ser contemplados aspectos como imagens, cores, fontes, grifos, negritos, layout, elementos de fundo, som, movimentos, seleção lexical, suporte, dentre outras possibilidades; (vi) o ensino remoto possui um caráter multimodal, concretiza-se na exploração das diversas semioses, explora os múltiplos recursos e linguagens, visando ampliar a comunicação docente e romper distâncias; e (vii) na comunicação didática, o professor deve explorar a dialogicidade (imagem, ângulo, ritmo e gesto), visando maior interação, pois são recursos que podem minimizar dois problemas que tendem a se agravar com o distanciamento social: a evasão e a desistência.

Após a contextualização do revozeamento teórico presente nas ações didático-pedagógicas concretizadas no contexto escolar, tendo em vista, sobretudo, a concepção de multiletramentos, discorremos a seguir sobre os recursos que agenciamos para a comunicação didática.

\subsection{Recursos para a comunicação didática}

Quando falamos em intencionalidade didática, estamos nos referindo a ações organizadas e planejadas de modo consciente. Isso inclui a organização de conteúdos, a metodologia, a postura a ser adotada em sala e a seleção de recursos que farão a ponte comunicativa entre o professor e o aluno. No ambiente da sala de aula, o objetivo é que haja, de fato, a aprendizagem e, para isso, a interação entre os envolvidos é de total importância. Essa possibilitará ao aluno explorar, organizar e conectar seus pensamentos com os novos conhecimentos, pois "educação é comunicação, é diálogo na medida em que não é só transferência de saber, mas um encontro de sujeitos interlocutores que buscam a significação dos significados" (Freire, 1979, p. 69).

Nessa direção, a tarefa de ensinar tem sido cada vez mais desafiadora para o professor, uma vez que o ambiente social em que o discente vive, suas emoções, seus interesses pessoais e vários outros fatores interferem, e muito, nesse processo. Assim, é preciso pensar quais ações serão aplicadas e quais recursos didáticos possibilitarão o aprendizado, considerando as individualidades e a coletividade do processo de ensino.

De acordo com Souza (2007, p. 111), "recurso didático é todo material utilizado como auxílio no ensinoaprendizagem do conteúdo proposto para ser aplicado, pelo professor, a seus alunos". Para Sant'Anna e Sant'Anna (2004, p. 23), "[...] recursos de ensino é o conjunto de meios materiais, físicos e humanos que auxiliam o professor e o aluno na interação do processo ensino-aprendizagem [...]”. São inúmeros os exemplos: livros, mapas, objetos físicos, fotografias, gravuras, fitas gravadas, estudos dirigidos, filmes, jornais, revistas, cartazes, televisores, quadros, entre outros.

Desse modo, é salutar que o docente aplique a maior variedade possível desses recursos, considerando seus objetivos e o grupo para o qual leciona, a fim de possibilitar a esses indivíduos maior engajamento, autonomia, aprofundamento, aplicação dos conhecimentos e produção de novos saberes. Segundo Merieu (1998, p. 40), 
O ofício de ensinar requer esta dupla e incansável prospecção, por um lado, no que diz respeito aos sujeitos, às suas aquisições, suas capacidades, seus recursos, seus interesses, seus desejos e, por outro lado, no que diz respeito aos saberes que devem ser incessantemente percorridos, inventariados para neles descobrir novas abordagens, novas riquezas, novas maneiras de apresentação.

Contudo, diante do cenário imposto pela pandemia, o processo de ensino tornou-se ainda mais desafiador. Nesse período, os esforços tanto de professores quanto de alunos se intensificaram para a manutenção dos vínculos necessários para desenvolvimento gradativo do ensino e da aprendizagem. Porém, as ações docentes, em especial, precisaram ser reordenadas e adaptadas a fim de construir relações educacionais, e também afetivas, por meio da comunicação e dos recursos virtuais, até então não tão comuns nos ambientes escolares.

O professor, agora distante fisicamente de seus alunos, vê reduzida a sua capacidade de acompanhar ações, antes habituais, como: realização de atividades individuais e em grupos, identificação de possíveis dúvidas, correção, intervenção imediata, interação não verbal com o outro, entre outras possibilitadas pelo contato presencial em sala de aula. Segundo Moran (2018, p. 35), “aprendemos quando alguém mais experiente nos fala e aprendemos quando descobrimos a partir de um envolvimento mais direto, por questionamento e experimentação (a partir de perguntas, pesquisas, atividades, projetos)”.

Essas práticas mencionadas por Moran (2018), embora eficazes e fundamentais, nem sempre se realizaram do modo desejado em todas as aulas presenciais, porém, na educação no formato remoto, sua execução torna-se ainda mais trabalhosa. Assim, diante desse cenário, no qual a interação não ocorre da mesma forma, a comunicação, mais do que nunca, precisa ser sempre clara, para indicar o que o aluno deve fazer e como deve fazê-lo, para que haja, de fato, a aprendizagem. Daí, a necessidade de se instaurarem "guias", como no caso do roteiro de autoestudo para esse propósito.

De acordo com Das et al.(2019), no nível superior, mais especificamente nos cursos de graduação, a aprendizagem direcionada aos alunos deve contemplar princípios da teoria da Andragogia, visto que diz respeito à questão da aplicabilidade do saber atrelado à prática profissional, uma vez que os saberes devem ter utilidade no mundo do trabalho. Para tanto, questões como o desenvolvimento do autodidatismo são essenciais, o que justifica a proposição do roteiro de autoestudo.

As pesquisas de Das et al. (2019) destacam a relevância de a educação superior priorizar ao aluno aprendizagens reais, tanto que os autores exemplificam com o resultado das pesquisas realizadas pelo RMIT International University, cujos resultados apontam que, quando os alunos adultos exploram os letramentos digitais, por meio de atividades que priorizam o autoestudo/via autonomia discente, o resultado é a permanência do aluno na escola, evitando, assim, a evasão escolar. Nesse sentido, Dudeney, Hockly e Pegrum (2016, p. 17) destacam que os letramentos digitai são "habilidades individuais e sociais necessárias para interpretar, administrar, compartilhar e criar sentido eficazmente no âmbito crescente de comunicação digital”.

Tento versado sobre os recursos para a interação didática, na sequência, versamos sobre o gênero "roteiro" atrelado às práticas de ensino na arquitetura escolar.

\subsection{O gênero "roteiro" nas práticas de ensino}

O dicionário Caldas Aulete (2008, p. 882) nos traz as seguintes acepções para o vocábulo "roteiro": "trajeto de viagem; planejamento prévio de uma atividade: roteiro de estudos; texto com enredo de um filme, peça teatral etc.”.

$\mathrm{Na}$ busca por trabalhos acadêmicos sobre a temática "roteiro", nosso objeto de discussão neste trabalho, observamos certa carência de produções que definam e caracterizem o gênero na esfera escolar; o que mais encontramos diz respeito à apresentação do processo de roteirização, com ênfase na área cinematográfica. Price (2017, p. 324) justifica tal contexto, asseverando haver certa marginalização que permeia esse gênero, pois considera-se o roteiro "muito literário para a área de estudo fílmico e muito cinemático para os departamentos de literatura". 
Mediante o exposto, recorremos aos estudos de Bakhtin (2010) e seus caudatários e assumimos o roteiro como um gênero discursivo, na acepção bakhtiniana. Isso posto, o gênero "roteiro" molda-se/adapta-se, de acordo com as necessidades humanas, e sofre influência da finalidade e do contexto, circulando em diferentes esferas de atividade humana (Bakhtin, 2010).

Assim, embora o Dicionário Caldas Aulete (2008) apresente as várias possibilidades de uso de um roteiro em múltiplas práticas sociais, vemos que todas têm como ponto assoante ser um gênero que nos possibilita procedermos a uma organização sequencial de ações, a fim de atingirmos determinada finalidade, dentro de determinado contexto e da esfera de circulação (Bakhtin, 2010).

Para este trabalho, devido aos objetivos já elencados, caracterizamos o gênero como "roteiro de autoestudo", considerando os três elementos do gênero discursivo apresentados por Bakhtin (2010, p. 262): o conteúdo temático, o estilo e a construção composicional, sendo "indissoluvelmente ligados no todo do enunciado e são igualmente determinados pela especificidade de um determinado campo da comunicação".

A partir de tais proposições, organizamos a caracterização, conforme Quadro 1, indicando os elementos os elementos constitutivos do gênero "roteiro de autoestudo":

Quadro1 - Caracterização do gênero "roteiro de autoestudo".

\begin{tabular}{|l|l|}
\hline 1) Contexto de produção e relação autor-leitor-texto \\
\hline Enunciador & Professor \\
\hline Destinatário & Aluno \\
\hline Local e época de circulação & $\begin{array}{l}\text { Norte do Paraná, no contexto do Ensino Remoto Emergencial, sendo a esfera de atividade humana a } \\
\text { acadêmica. }\end{array}$ \\
\hline Objetivo da interação & $\begin{array}{l}\text { Instruir o aluno sobre o desenvolvimento de ações sequenciais que o auxiliem na realização de } \\
\text { atividades propostas, promovendo o autoestudo e a autonomia. }\end{array}$ \\
\hline 2) Assunto (o conteúdo temático vai se construindo dialogicamente) \\
\hline $\begin{array}{l}\text { O roteiro de autoestudo apresenta instruções sequenciais para o aluno, a fim de o auxiliar no desenvolvimento do autoestudo e da } \\
\text { autonomia, no momento da realização de atividades propostas. }\end{array}$ \\
\hline 3) Construção composicional do gênero "roteiro de autoestudo" \\
\hline $\begin{array}{l}\text { Dados da disciplina; texto introdutório com informações gerais; exploração da multimodalidade (fotos/imagens/gráficos/infográficos, } \\
\text { etc.); textos para as atividades com hiperlinks; texto de encerramento. }\end{array}$ \\
\hline 4) Marcas linguístico-enunciativas \\
\hline $\begin{array}{l}\text { Linguagem formal, presença da seleção lexical que promova maior dialogicidade: (i) seleção lexical mais impessoal (ex. uso de "você", } \\
\text { "olá", "até mais", "até nosso próximo encontro"); (ii), uso da primeira pessoa do plural, visando à aproximação e à inserção do aluno no } \\
\text { texto (ex.: "nós", "pesquisamos"); (iii) exploração de perguntas retóricas reflexivas; (iv) uso de discurso direto; (v) seleção lexical que } \\
\text { faça retomadas, a fim de o aluno construir conexões com saberes prévios; (vi) predomínio de verbos no imperativo para instruções (ex.: } \\
\text { "pesquise", "faça"); (vii) uso da condicional "se" ou expressões similares, a fim de promover a autonomia do aluno (ex.: "se desejar"); } \\
\text { (viii) inserção de textos multimodais (imagens, hiperlinks, etc.). }\end{array}$ \\
\hline
\end{tabular}

Fonte: Autores, com base em Bakhtin (2010) e Rojo (2012).

De acordo com as proposições do Quadro 1, é possível asseverar que o gênero "roteiro de autoestudo" tem uma estrutura composicional que, de acordo com a finalidade e o contexto, pode ser adaptada/reconfigurada, a fim de atender à situação interacional. Da mesma forma, temos a seleção lexical presente no texto, e esta é responsável pelos possíveis pluri e múltiplos sentidos, pois as palavras possuem maior ou menor peso semântico, dentro do contexto de produção.

Diante do exposto, nossa proposta é a de que o roteiro de autoestudo possa ser um instrumento eficaz para o aluno, uma vez que permite atuação autônoma no âmbito do ensino remoto. 


\section{Procedimentos Metodológicos}

A proposta deste trabalho emerge de um contexto de atuação prática, retomando as experiências vivenciadas por um dos autores, como professor de um Curso de Letras, no âmbito do ensino remoto. Dada essa especificidade, metodologicamente, a pesquisa comporta as premissas caracterizadoras de um estudo de caso, que, no âmbito dos estudos de base qualitativa, segundo Paiva (2019, p. 67), baseada em Yin (2001, p. 32), consiste numa "investigação empírica", com a exploração de um "fenômeno contemporâneo dentro de seu contexto da vida real". Trata-se, em síntese, de "um estudo naturalístico porque estuda um acontecimento em um ambiente natural e não criado exclusivamente para a pesquisa” (Paiva, 2019, p. 65).

Para as análises, conforme previamente registrado, os autores partem de duas fontes principais: a estrutura do roteiro de autoestudo implementado pelo professor como recurso para facilitar o processo de comunicação didática entre ele e seus alunos; e as percepções desses alunos acerca da utilização desse material no desenvolvimento de suas atividades acadêmicas. Dessa forma, considerando-se esse material-fonte plural, mobilizam-se princípios metodológicos da chamada documentação indireta, que, segundo Marconi e Lakatos (2003, p. 174), está atrelada a um procedimento básico de toda pesquisa: o "levantamento de dados de variadas fontes, quaisquer que sejam os métodos ou técnicas empregadas".

No que tange especificamente à análise da estrutura do roteiro de autoestudo, parte-se de um exemplar, selecionado pelo professor autor da proposta, desenvolvido para um encontro de duas aulas de 50 min de uma das disciplinas ministradas por ele (Metodologia do Ensino de Português II), voltada a discussões sobre a atuação do professor de Língua Portuguesa no Ensino Médio. No caso em questão, trata-se de um roteiro que orienta atividades teórico-práticas baseadas no tema "Elaboração de enunciados", conforme organização visual apresentada na Figura 1, a seguir:

Figura 1 - Organização visual do roteiro de autoestudo selecionado.

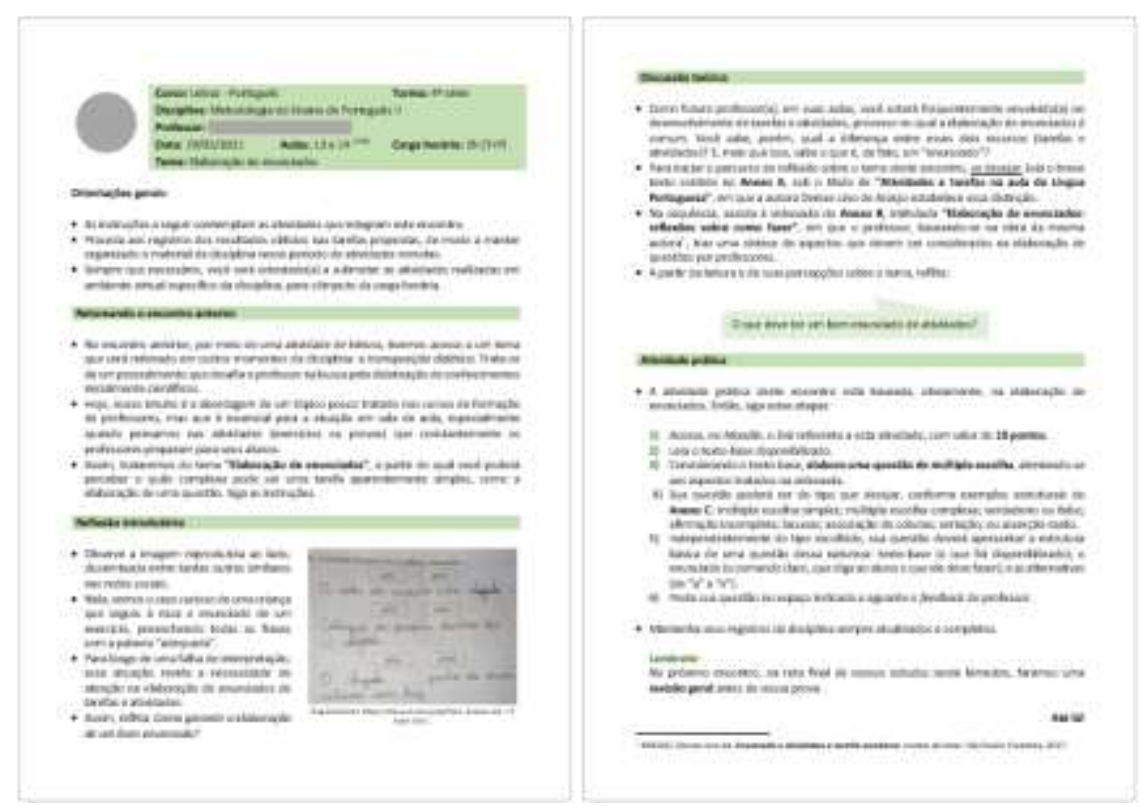

Fonte: Guerra Junior (2021).

A Figura 1 objetiva fornecer ao leitor uma visão como um todo do roteiro de autoestudo, a fim de demonstrar que ele pode ser objetivo, limitando-se a duas laudas. A estrutura do roteiro, cujo conteúdo é apresentado em detalhes posteriormente, será analisada a partir de enfoques específicos, como descreve o Quadro 2, na sequência: 
Quadro 2 - Decomposição estrutural do roteiro de autoestudo para análise.

\begin{tabular}{|l|l|}
\hline Seção & Foco da análise \\
\hline Orientações gerais & Documentação de aspectos normativos \\
\hline Retomando o encontro anterior & Organização sequencial dos encontros ministrados \\
\hline Reflexão introdutória & Contextualização do tema / conteúdo do encontro \\
\hline Discussão teórica & Base teórico-metodológica adotada no encontro \\
\hline Atividade prática & Dinâmica do processo avaliativo instaurado no encontro \\
\hline Lembrete & Organização sequencial dos encontros ministrados \\
\hline
\end{tabular}

Fonte: Autores.

Conforme pode ser observado pelos aspectos elencados no Quadro 2, as ações registradas pelo roteiro, ao delinearem um percurso gradativo, são integradas aos pressupostos epistemológicos vygotskyanos, ou seja, parte-se do nível de desenvolvimento atual dos alunos, considerando-se seus conhecimentos prévios, e, paulatinamente, insere-se a construção do conhecimento científico, a fim de que sejam incorporados conceitos que impulsionem o aluno para outro nível de aprendizagem, promovendo maior autonomia no processo de ensino (Vygotsky, 1999).

Por sua vez, no que concerne à análise das percepções dos alunos, parte-se das enunciações registradas por 20 alunos matriculados em diferentes disciplinas ministradas pelo professor (Metodologia do Ensino de Português II e Morfossintaxe), em um breve questionário, direcionado aos acadêmicos via plataforma Google Forms, para participação voluntária, solicitando-se um posicionamento diante das seguintes questões²:

- Você considera importante, no ensino remoto, a disponibilização de roteiros de autoestudo para o desenvolvimento das disciplinas?

- Como você avalia os roteiros de autoestudo disponibilizados?

Os dados compilados a partir das entradas computadas no formulário digital indicam, para a primeira questão, um total de $100 \%$ no total de alunos que atribuem ao roteiro de autoestudo um caráter de relevância, o que evidencia a aceitabilidade do corpo discente perante o recurso. Assim, as análises a serem apresentadas concentram-se na avaliação dos acadêmicos, foco do segundo item, sendo as percepções registradas distribuídas em categorias específicas, conforme descrição do Quadro 3, a seguir:

Quadro 3 - Categorização das percepções sobre o roteiro de autoestudo para análise.

\begin{tabular}{|l|l|}
\hline Categoria & Foco da análise \\
\hline $\begin{array}{l}\text { Roteiro como } \\
\text { "mediador da aprendizagem" }\end{array}$ & Contribuições do roteiro no desenvolvimento de atividades \\
\hline $\begin{array}{l}\text { Roteiro como } \\
\text { "fonte de conteúdo" }\end{array}$ & Contribuições do roteiro no aprofundamento teórico da disciplina \\
\hline $\begin{array}{l}\text { Roteiro como } \\
\text { "marcador temporal" }\end{array}$ & Contribuições do roteiro na progressão curricular da disciplina \\
\hline $\begin{array}{l}\text { Roteiro como } \\
\text { "exemplo de prática docente" }\end{array}$ & Contribuições do roteiro na formação inicial dos futuros professores \\
\hline
\end{tabular}

Fonte: Autores.

\footnotetext{
${ }^{2}$ Além das respostas às duas questões aqui elencadas, o formulário, ao final, trazia um espaço para que os alunos, se desejassem, pudessem registrar sugestões de melhorias no material. Considerando que poucos alunos se manifestaram nesse item, e dadas as características dos dados, essas informações não integram as categorias de análise, sendo registradas apenas como informações complementares nas considerações finais do trabalho.
} 
Articulando-se os agrupamentos categoriais apresentados no Quadro 2 e, agora, no Quadro 3 (análise da estrutura do roteiro de autoestudo e análise das percepções dos alunos, respectivamente), estabelecemos um diálogo com pressupostos advindos dos estudos bakhtinianos. No primeiro caso, trabalha-se com a estrutura composicional, um dos elementos constitutivos de todo e qualquer gênero discursivo, que assume uma dada configuração no âmbito de uma situação interacional. No segundo caso, com ênfase nos sentidos emergentes do campo semântico dos enunciados selecionados, numa perspectiva bakhtiniana, as análises consideram a seleção lexical, o papel discursivo dos sujeitos, o contexto e o momento sócio-históricocultural (Bakhtin, 2010).

Na próxima seção, portanto, a partir das delimitações metodológicas aqui discutidas, apresentamos os resultados das análises.

\section{Resultados e Discussão}

A discussão dos dados busca, neste trabalho, sustentar o estudo de caso que o configura teórico-metodologicamente. Dessa forma, articulamos informações provenientes de transcrições, tanto de informações contidas no exemplar de roteiro de autoestudo selecionado, para a análise de seus componentes estruturais, quanto das percepções dos alunos sobre o material, para a análise da eficácia didática do recurso. Tais dados são apresentados na sequência, mobilizando-se as seções e categorias previamente estipuladas (conforme Quadros 2 e 3).

\subsection{Análise da estrutura do roteiro de autoestudo}

Neste item, o roteiro de autoestudo é analisado a partir de sua organização estrutural, considerando-se as seções relacionadas no Quadro 2: orientações gerais; retomando o encontro anterior; reflexão introdutória; discussão teórica; atividade prática; e lembrete.

\subsubsection{Seção "orientações gerais"}

Nesta seção, o exemplar do roteiro de autoestudo selecionado exibe o seguinte conteúdo:

- As instruções a seguir contemplam as atividades que integram este encontro.

- Proceda aos registros dos resultados obtidos nas tarefas propostas, de modo a manter organizado o material da disciplina nesse período de atividades remotas.

- Sempre que necessário, você será orientado(a) a submeter as atividades realizadas em ambiente virtual específico da disciplina, para cômputo da carga horária.

Como o próprio título da seção sugere, e tomando por base o conteúdo dos enunciados dispostos nessa parte do roteiro de autoestudo, verificamos o caráter genérico e replicável das informações, as quais não estão atreladas a um conteúdo específico, funcionando apenas como diretrizes a serem consideradas pelo aluno no desenvolvimento de suas atividades, de forma bem delimitada: a inscrição "neste encontro" estabelece o espaço de ensino-aprendizagem sobre o qual o documento tem influência.

Além disso, tais diretrizes manifestam-se em outra dimensão: no âmbito "legal", administrativo, o roteiro preocupa-se em orientar o acadêmico à documentação das tarefas realizadas, a fim de, especialmente em se tratando de ensino remoto, garantir o registro de dados que, efetivamente, comprovem o cumprimento da carga horária, cujo cômputo depende também de registros em sistemas digitais, como o "ambiente virtual" mencionado. 


\subsubsection{Seção "retomando o encontro anterior"}

Nesta seção, o exemplar do roteiro de autoestudo selecionado exibe o seguinte conteúdo:

- No encontro anterior, por meio de uma atividade de leitura, tivemos acesso a um tema que será reiterado em outros momentos da disciplina: a transposição didática. Trata-se de um procedimento que desafia o professor na busca pela didatização de conhecimentos inicialmente científicos.

- Hoje, nosso intuito é a abordagem de um tópico pouco tratado nos cursos de formação de professores, mas que é essencial para a atuação em sala de aula, especialmente quando pensamos nas atividades (exercícios ou provas) que constantemente os professores preparam para seus alunos.

- Assim, trataremos do tema "Elaboração de enunciados", a partir do qual você poderá perceber o quão complexa pode ser uma tarefa aparentemente simples, como a elaboração de uma questão. Siga as instruções.

A essência dessa seção é a temporalidade, ou seja, a marcação sequencial do processo de ensino-aprendizagem, do qual o encontro em que se insere o roteiro de autoestudo em análise é apenas uma parte. Assim, numa escala temporal, as instruções do roteiro movimentam-se em duas direções: um "antes"; e um "agora".

Primeiramente, recorre-se ao emprego da expressão adverbial "no encontro anterior", a partir da qual é introduzida uma breve síntese das ações empreendidas previamente no desenvolvimento da disciplina, acionando os conhecimentos prévios dos alunos, com retomadas que os auxiliem na construção de saberes (Vygotsky, 1999). Depois, por meio do advérbio "hoje", instaura-se uma breve contextualização, que estabelece as bases para a apresentação explícita do tema a ser contemplado no encontro em curso.

A seção é finalizada com a expressão injuntiva "siga as instruções", que evoca, explícita e linguisticamente, a natureza do gênero roteiro de autoestudo.

\subsubsection{Seção "reflexão introdutória"}

Nesta seção, o exemplar do roteiro de autoestudo selecionado exibe o seguinte conteúdo:

- $\quad$ Observe a imagem reproduzida ao lado [aqui, reproduzida abaixo, na Figura 2], disseminada entre tantas outras similares nas redes sociais.

- Nela, vemos o caso curioso de uma criança que seguiu à risca o enunciado de um exercício, preenchendo todas as frases com a palavra "adequada".

- Para longe de uma falha de interpretação, essa situação revela a necessidade de atenção na elaboração de enunciados de tarefas e atividades.

- $\quad$ Assim, reflita: Como garantir a elaboração de um bom enunciado?

Figura 2 - Exemplo de enunciado mal formulado apresentado no roteiro.

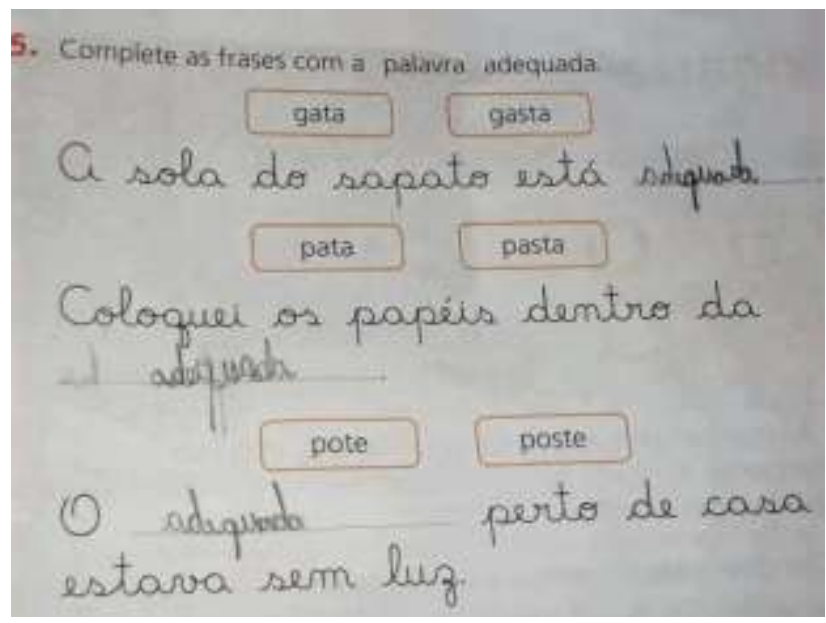

Fonte: Google Imagens (2021). 
A Figura 2 exemplifica que essa seção surge em consonância com as mais recentes tendências educacionais, uma vez que: propõe um movimento reflexivo atrelado ao processo de formação; e mobiliza diferentes códigos, unindo palavra e imagem.

Assim como a seção anterior, esse segmento do roteiro também assume uma função contextualizadora, por dialogar diretamente com o tema previamente indicado ("Elaboração de enunciados"). Ao mobilizar a imagem apresentada, além de revestir sua proposta de um caráter multimodal (Rojo, 2012), o roteiro ilustra situações reais bastante próximas daquelas a serem vivenciadas pelo aluno em sua prática profissional.

Por fim, a inserção de um questionamento reflexivo, de forma direta e sem qualquer tipo de discussão complementar, encerra a seção como um convite ao aluno, a fim de que avance para as próximas etapas e, assim, por meio do estudo a ser realizado, alcance suas conclusões.

\subsubsection{Seção "discussão teórica"}

Nesta seção, o exemplar do roteiro de autoestudo selecionado exibe o seguinte conteúdo:

- Como futuro professor(a), em suas aulas, você estará frequentemente envolvido(a) no desenvolvimento de tarefas e atividades, processo no qual a elaboração de enunciados é comum. Você sabe, porém, qual a diferença entre esses dois recursos (tarefas e atividades)? E, mais que isso, sabe o que é, de fato, um "enunciado"?

- Para iniciar o percurso de reflexão sobre o tema deste encontro, se desejar, leia o breve texto contido no Anexo A, sob o título de "Atividades e tarefas na aula de Língua Portuguesa", em que a autora Denise Lino de Araújo estabelece essa distinção.

- Na sequência, assista à videoaula do Anexo B, intitulada "Elaboração de enunciados: reflexões sobre como fazer", em que o professor, baseando-se na obra ${ }^{3}$ da mesma autora , traz uma síntese de aspectos que devem ser considerados na elaboração de questões por professores.

- A partir da leitura e de suas percepções sobre o tema, reflita: O que deve ter um bom enunciado de atividades?

A seção delineia, em certa medida, o ponto fulcral do desenvolvimento do encontro orientado pelo roteiro em análise. Isso se deve ao fato de que é nesse momento que se estabelece o confronto entre diferentes saberes - um prévio, decorrente das experiências vivenciadas pelo aluno em sua trajetória de vida; e um sistematizado, pautado em concepções teóricas, imprescindíveis à formação acadêmica (Vygotsky, 1999).

Dessa forma, o roteiro apresenta os recursos (videoaula e texto) mobilizados como base teórico-metodológica para as ações subsequentes. Tem-se, nessa apresentação, mais uma vez, um processo que convoca o aluno à reflexão, com a inserção de diferentes questionamentos, antes e depois da apresentação desses materiais, oferecendo a ele alguns parâmetros norteadores para o seu estudo.

Vale ressaltar, também nesse segmento, o caráter flexível do roteiro: a expressão condicional “se desejar” marca a possibilidade de o aluno agir, pelo menos em parte, de modo autônomo, numa tomada de decisão que o permite participar da construção do seu processo de aprendizagem.

\subsubsection{Seção "atividade prática"}

Nesta seção, o exemplar do roteiro de autoestudo selecionado exibe o seguinte conteúdo:

- A atividade prática deste encontro está baseada, obviamente, na elaboração de enunciados. Então, siga estas etapas:

1) Acesse, no Moodle, o link referente à esta atividade, com valor de 10 pontos.

\footnotetext{
${ }^{3} \mathrm{O}$ roteiro faz menção à obra de Araújo (2017).
} 
2) Leia o texto-base disponibilizado.

3) Considerando o texto-base, elabore uma questão de múltipla escolha, atentando-se aos aspectos tratados na videoaula.

4) Sua questão poderá ser do tipo que desejar, conforme exemplos estruturais do Anexo C: múltipla escolha simples; múltipla escolha complexa; verdadeiro ou falso; afirmação incompleta; lacunas; associação de colunas; seriação; ou asserção-razão.

5) Independentemente do tipo escolhido, sua questão deverá apresentar a estrutura básica de uma questão dessa natureza: texto-base (o que foi disponibilizado); o enunciado (o comando claro, que diga ao aluno o que ele deve fazer); e as alternativas (de "a" a "e").

6) Poste sua questão no espaço indicado e aguarde o feedback do professor.

- Mantenha seus registros da disciplina sempre atualizados e completos.

As informações que preenchem esse segmento do roteiro de autoestudo se sustentam no binômio teoria-prática, considerando que é instaurada a possibilidade de o aluno aplicar, numa tarefa específica, os conceitos contemplados na abordagem epistemológica antecedente. Merecem destaque, na exploração das marcas dessa seção, o caráter processual da atividade, com a descrição das diferentes etapas a serem percorridas pelo aluno, além da diversidade de recursos mobilizados: texto-base; material anexo complementar; e suporte digital (ambiente para postagem da proposta elaborada).

O texto-base, embora não mencionado no roteiro, constitui uma importante peça na composição multimodal do encontro - trata-se de uma tirinha, gênero discursivo marcado pela articulação de diferentes linguagens. Além disso, ao congregar diferentes habilidades - como não só analisar um texto para elaborar uma questão como também gerar um arquivo dessa produção e inseri-lo num sistema -, a atividade dá espaço aos multiletramentos (Rojo, 2012) incluindo os letramentos digitais (Dudeney, Hockly, \& Pegrum, 2016).

Por fim, numa última sequência injuntiva, o roteiro reitera ao aluno a necessidade de manutenção dos registros, numa clara menção a estratégias de estudo.

\subsubsection{Seção "lembrete"}

Nesta seção, o exemplar do roteiro de autoestudo selecionado exibe o seguinte conteúdo:

No próximo encontro, na reta final de nossos estudos neste bimestre, faremos uma revisão geral antes de nossa prova. Até lá!

Assim como na seção "retomando o encontro anterior", a seção "lembrete" tem na temporalidade a sua estruturação enunciativa. Dessa forma, marcações linguísticas que remetem a um "depois" - a expressão adverbial "no próximo encontro" e a flexão verbal no futuro do presente, em "faremos" - conectam as tarefas executadas pelo aluno a uma espécie de linha do tempo próxima de sua finalização.

Adicionalmente, ficam evidentes aqui, mais uma vez, aspectos normativos, como o atendimento a um sistema avaliativo institucionalizado, considerando que a menção a uma "revisão geral" e, por fim, a uma "prova" torna explícita a adoção de mecanismos específicos para a aferição da aprendizagem do aluno.

\subsection{Análise das percepções dos acadêmicos sobre o roteiro de autoestudo}

Neste item, o roteiro de autoestudo é analisado a partir das percepções avaliativas dos alunos, as quais sugerem sua eficácia didática, considerando-se as categorias relacionadas no Quadro 3: roteiro como mediador da aprendizagem; roteiro como fonte de conteúdo; roteiro como marcador temporal; e roteiro como exemplo de prática docente. 


\subsubsection{Categoria "roteiro como mediador da aprendizagem"}

Nesta categoria, as enunciações ${ }^{4}$ dos alunos revelam as seguintes percepções:

(1) "Os roteiros são indispensáveis. Ajudam muito na fixação de conteúdos e deixam as atividades muito mais claras."

(2) "De acordo com o meu desempenho no ensino remoto, o roteiro é algo que auxilia muito na minha aprendizagem."

(3) "Os roteiros colaboram para retomada de conteúdo, o que considero importante, já que temos várias matérias com o mesmo professor, e é possível haver 'erros'. Além de ser facilitador para o conhecimento a seguir."

(4) "Extremamente didáticos; auxiliam de maneira significativa o desenvolvimento das atividades; possuem leitura simples, são objetivos e contêm exemplificações diversas e dinâmicas."

(5) "Acho a ideia do roteiro fundamental pelo fato de organizar as nossas disciplinas e o andamento da aula, com eles fica bem mais fácil entender o que deve ser realizado na aula."

(6) "Cumpre muito bem o objetivo de um roteiro. No caso do roteiro da disciplina, considero de muita relevância, garantindo que o processo não fique 'perdido/bagunçado'."

(7) "Eu avalio os roteiros de autoestudo como ótimos, já que nos auxiliam bastante na realização das atividades propostas."

(8) "Acredito que colabora para nossa formação e faz com que aprendamos, bem como fiquemos mais localizados."

(9) "São ótimos os roteiros de autoestudo, pois ajudam bastante em nossa aprendizagem."

(10) "Os roteiros ajudam e esclarecem o conteúdo durante o estudo."

(11) "Muito bons, nos direcionam para como estudar o conteúdo."

(12) "Uma vez que não estou na sala de aula com um contato próximo com o professor, o roteiro realiza essa mediação esclarecendo o conteúdo."

As proposições defendidas por meio dos excertos centram-se no roteiro de autoestudo enquanto uma ferramenta auxiliar, como em (3), que menciona a "retomada de conteúdo", e em (4), que cita o "desenvolvimento das atividades", além de prosseguir com a argumentação pautada no fato de que esses recursos "possuem leitura simples, são objetivos e contêm exemplificações diversas e dinâmicas”.

De modo complementar, em (10) e (11), respectivamente, os alunos asseveram que o roteiro de autoestudo é facilitador da aprendizagem, pois nele temos ações norteadoras que "esclarecem o conteúdo durante o estudo", o que tende a direcioná-los a "estudar o conteúdo".

Diante disso, destacamos as proposições contidas em (12), segundo a qual o roteiro de autoestudo "realiza essa mediação esclarecendo o conteúdo", e em (8), que pontua o apoio do roteiro na localização dos estudantes: “faz com que aprendamos, bem como fiquemos mais localizados". Tais proposições dialogam com (7), quando um dos alunos enuncia que os roteiros "auxiliam bastante na realização das atividades propostas".

Adicionalmente, sintetizamos com as asserções contidas em (5), em que um aluno defende a essencialidade do roteiro de autoestudo, a partir da seguinte justificativa: "pelo fato de organizar as nossas disciplinas e o andamento da aula, com eles fica bem mais fácil entender o que deve ser realizado na aula”. Isso é corroborado por (6): "Cumpre muito bem o objetivo de um roteiro. No caso do roteiro da disciplina, considero de muita relevância, garantindo que o processo não fique 'perdido/bagunçado"”.

Como podemos observar, pelas proposições dos alunos, os sentidos que emanam das seleções lexicais nos remetem aos estudos de Buckinghan (2010), sobretudo no que tange ao fato de o aluno desenvolver habilidades que o auxiliem a se organizar tanto na seleção quanto na localização de materiais.

Mediante o exposto, aferimos que a mediação da aprendizagem é essencial. No ensino remoto, em que o contato presencial é suprimido e em que essa tarefa (a mediação) se mantém na dependência de recursos digitais, é necessária a adoção de estratégias que, em certa medida, potencializem a interação professor-aluno.

\footnotetext{
${ }^{4}$ Fragmentos enumerados sequencialmente para facilitar a retomada no percurso de análise.
} 
Diante das percepções reunidas, o roteiro de autoestudo é considerado um "mediador da aprendizagem", na medida em que, para os alunos, ele: fixa, retoma, esclarece conteúdos; clarifica e explica atividades; diversifica e dinamiza exemplos; organiza processos; localiza e aponta caminhos; enfim, como explicita (12), "realiza essa mediação".

\subsubsection{Categoria "roteiro como fonte de conteúdo"}

Nesta categoria, as enunciações dos alunos revelam as seguintes percepções:

(13) "Excelente, pois ele nos ajuda muito. Nele contém o que precisamos saber para realizarmos aquela aula!"

(14) "Me ajuda muito quando possui uma atividade, por exemplo, consigo consultar e tirar minha dúvida."

(15) "Avaliado como um suporte importante que complementa a aprendizagem dos conteúdos."

(16) "Um pré-conteúdo, algo extremamente essencial para se localizar nos estudos."

(17) “Os roteiros são excelentes ainda mais quando contém hiperlinks dos conteúdos (textos auxiliares) para que possamos acessar os documentos citados no próprio roteiro sem ter que ficar procurando no Moodle qual texto está sendo discutido."

Destacamos os excertos estruturados em torno de uma seleção lexical que evidencia a relevância de o aluno ter um direcionamento do professor, no sentido de o docente indicar caminhos que o orientem, adequadamente, nesse autoestudo. É o que apontam enunciados como o (13): "nos ajuda muito [...] contém o que precisamos saber para realizarmos aquela aula!" Além do conteúdo que valoriza o auxílio obtido por meio do roteiro, vale ressaltarmos o emprego da pontuação: o sinal de exclamação, em certa medida, ao direcionar nossa leitura, recobre a expressão "aquela aula" de um caráter específico, na acepção de ser "a" aula, uma aula devidamente preparada, ao encontro das possíveis necessidades dos alunos.

Em (15), por sua vez, um respondente mobiliza o termo "suporte" e atrela o autoestudo à complementação da “aprendizagem dos conteúdos”. Já nas proposições de (16), encontramos o que pode ser associado à noção de uma pré-aula no sentido de referir-se a uma antecipação do que será abordado no encontro com o professor, quando o aluno destaca a relevância de um "pré-conteúdo", avaliando-o como "algo extremamente essencial para se localizar nos estudos". Dito em outras palavras, trata-se de algo importante para a identificação daquele saber, por isso é "essencial" para "se localizar" algo, no sentido da assertividade do saber, afinal toda aula é um recorte, atrelado a um conteúdo programático, colocado em prática via uma sequência de atividades docentes.

A enunciação de (17) define os roteiros e os contextualiza dentro dos letramentos atuais, pois considera a multimodalidade e os letramentos digitais. Contudo, estes devem ser adequados ao conteúdo temático e à finalidade discursiva. Logo, quando (17) enuncia que os roteiros são definidos como “excelentes", o estudante estabelece critérios para uma avaliação gradativa, ou seja, apresenta as condições necessárias para que os recursos sejam ainda melhores: "ainda mais quando contém hiperlinks dos conteúdos (textos auxiliares) para que possamos acessar os documentos citados no próprio roteiro sem ter que ficar procurando no Moodle qual texto está sendo discutido".

Sumarizando, os excertos nos apontam que é crucial desenvolvermos no aluno a capacidade de ele "se envolver com as tecnologias digitais, algo que exige um domínio dos letramentos digitais necessários para usar eficientemente essas tecnologias", pois isso vai ajudá-lo a "localizar recursos, comunicar ideias e construir colaborações que ultrapassem os limites pessoais, sociais, econômicos, políticos e culturais" (Dudeney, Hockly, \& Pegrum, 2016, p. 17).

Assim, os atos de ensinar e aprender, além de muitas outras variáveis, demandam a existência de conteúdo, de informação. Isso é obtido a partir de diferentes recursos, os quais, numa visão tradicional, podem ser representados por livros,

${ }^{5}$ Fase típica da metodologia ativa da sala de aula invertida. 
textos e aulas (ou videoulas, como no caso do ensino remoto). No entanto, conforme as percepções dos alunos, o roteiro de autoestudo é igualmente considerado uma "fonte de conteúdo".

Segundo eles, o roteiro de autoestudo: disponibiliza as condições para a execução de tarefas; funciona como material de consulta para o esclarecimento de dúvidas; e complementa informações. Todas essas ações, considerando-se o contexto de aplicabilidade do roteiro, envolvem componentes informacionais atrelados a um dado tema, portanto a noção de conteúdo é evidente.

Vale destacar, nos enunciados registrados, a ideia de "pré-conteúdo", já que algumas etapas do roteiro (como observado na análise da sua estrutura) constituem propostas reflexivas preliminares, antes que o aluno alcance a abordagem teórica central do tema do encontro. Além disso, merece atenção a dimensão hipertextual do roteiro, instaurada a partir da possibilidade de inserção de hiperlinks, citada como um diferencial para o acesso a conteúdo para além dos limites do documento.

\subsubsection{Categoria "roteiro como marcador temporal"}

Nesta categoria, as enunciações dos alunos revelam as seguintes percepções:

(18) "O roteiro faz a recapitulação da aula anterior e organiza os pensamentos pra a próxima aula."

(19) "Acredito que sejam extremamente importantes, pois nos ajudam a organizar o nosso estudo dentro do período da aula. Nunca achei que um roteiro seria necessário até que tive acesso a um. Só aí pude perceber quanto eles cooperaram para a organização, principalmente pelo fato de apresentarem o trechinho relembrando o que estudamos na outra aula e fazendo o link com o próximo conteúdo."

(20) "Considero muito úteis os roteiros de autoestudo, principalmente porque auxiliam na organização das atividades propostas nas videoaulas. E quando não são acompanhados de videoaulas auxiliam na organização e priorização do que deve ser feito cronologicamente."

No que tange a esse aspecto da temporalidade, destacamos os excertos que retomam as postulações de Vygotsky (1999) relacionadas à progressão do aluno no percurso da aprendizagem. Em (18), por exemplo, é citada a "recapitulação da aula anterior", que possibilita organizar "os pensamentos pra a próxima aula", ou seja, os conhecimentos prévios, adicionados às intervenções pedagógicas, são alçados à condição de elementos essenciais para o avanço discente. Tal posição é reiterada por (19), que ressalta o papel do roteiro de autoestudo, "relembrando o que estudamos na outra aula e fazendo o link com o próximo conteúdo". Dito com outras palavras, trata-se de acionar os conhecimentos prévios, como pontuado por (18), mas ampliando as proposições. Retomam-se, assim, as asserções de Rojo (2012), no que diz respeito ao hipertexto, ou seja, um texto que remete a outros, ou de Lévy (1999), no sentido de um labirinto no qual temos hiperlinks que nos remetem a múltiplos textos.

Ainda no que tange às proposições de (19), é essencial destacarmos a quebra de paradigma, pois o estudante assevera: "Nunca achei que um roteiro seria necessário até que tive acesso a um." Uma asserção como essa nos permite inferir que, muitas vezes, experienciar ações novas pode resultar em ampliação dos saberes, tanto que o aluno prossegue afirmando que, a partir dessa vivência com os roteiros, ele pôde "perceber quanto eles cooperaram para a organização". Essa reflexão retoma Tardif (2014, p. 36), quando enuncia que o saber docente é "um saber plural, formado pelo amálgama, mais ou menos coerente, de saberes oriundos da formação profissional e de saberes disciplinares, curriculares e experienciais".

O enunciado de (20), por sua vez, nos remete à realidade do ERE, ou seja, os roteiros de autoestudo podem nos auxiliar "na organização das atividades propostas nas videoaulas. E quando não são acompanhados de videoaulas auxiliam na organização e priorização do que deve ser feito cronologicamente”. De fato, conforme estudo de Fonteque et al. (2021, p. 228), a pandemia alterou o cenário educacional e, mesmo na pós-pandemia, teremos os reflexos dos múltiplos letramentos 
requeridos num curto espaço de tempo: “Certamente, com o término deste longo período pandêmico, a educação não será mais a mesma, considerando-se que, muito provavelmente, outras formas de ensinar e aprender estarão em pauta, com a incorporação de ferramentas e/ou recursos".

Como já observado na análise dos componentes estruturais do roteiro de autoestudo, a temporalidade é a marca balizadora de algumas de suas seções, especificamente quando é retomado o encontro anterior e, ao final, quando se antecipa o objetivo do encontro seguinte. Em decorrência dessa organização sequencial, o roteiro é considerando pelos alunos, também, como um "marcador temporal".

Conforme os enunciados transcritos, o roteiro de autoestudo: estabelece-se como uma ponte entre a "aula anterior" e a "próxima aula"; organiza a produtividade acadêmica em um período específico (o "período da aula"); e define os objetivos a serem priorizados "cronologicamente" no desenvolvimento da disciplina.

\subsubsection{Categoria "roteiro como exemplo de prática docente"}

Nesta categoria, as enunciações dos alunos revelam as seguintes percepções:

(21) "É um instrumento que levarei para minha vida profissional, pois realmente acho muito útil a forma como organiza as ideias."

(22) "Os roteiros são claros, objetivos e didáticos."

Em relação aos sentidos evocados por essa categoria, observamos que o enunciado (21) ressalta a relevância de se apropriar da questão do roteiro de autoestudo para a vivência profissional, ou seja, destaca-se a ideia de que o professor precisa se organizar, mentalmente, para a aplicabilidade das proposições teórico-metodológicas. O fragmento (22), por sua vez, numa asserção bastante sucinta, permite a reflexão de que, se formos objetivos, no sentido de sabermos o que fazer, para que finalidade, em que contexto, otimizamos nossas ações.

Em um curso de graduação, em que o aluno está inserido em um processo de formação inicial, é imprescindível que sejam mobilizados exemplos de ordem prática e que integrem a dinâmica de sua futura atuação profissional. No caso de uma licenciatura, em que o objetivo central reside na formação de um "professor", muito do que é feito na condução das diferentes disciplinas pode ser deslocado como "exemplo de prática docente", como é o caso do roteiro de autoestudo, o que nos remete à necessidade de permitirmos ao aluno o desenvolvimento de habilidades como "criatividade e inovação, pensamento crítico e capacidade de resolução de problemas, colaboração e trabalho em equipe", indo além, pois se trata de termos - ou desenvolvermos - maior “autonomia e flexibilidade” (Dudeney, Hockly, \& Pegrum, 2016, p. 17).

Por ser considerado "didático", como relata um dos alunos, o roteiro de autoestudo reveste-se de uma especificidade: um elemento didático é aquele "destinado a instruir" (Houaiss, 2009), ou seja, que ensina. Ao ensinar, não o conteúdo, mas uma forma de atuação pedagógica, o roteiro de autoestudo é alçado a um instrumento de trabalho: "é um instrumento que levarei para minha vida profissional".

\section{Considerações Finais}

A proposta de construção deste texto pautou-se no objetivo de discutir a eficácia do "roteiro de autoestudo" como um recurso didático no âmbito do ensino remoto. Dessa forma, metodologicamente, as análises centraram-se em dois domínios categoriais: primeiro, buscamos compreender o modo como o instrumento pedagógico, enquanto gênero discursivo, é organizado estruturalmente; depois, exploramos o impacto da adoção do material na vivência acadêmica dos estudantes consultados. 
Em termos estruturais, concluímos que o roteiro de autoestudo apresenta uma organização processual, em que diferentes etapas se articulam com vistas à promoção de uma aprendizagem pautada na mobilização de diferentes linguagens e em diferentes níveis de aprofundamento, considerando-se conhecimentos básicos e sistematizados, bem como aliando gradientes teóricos e práticos.

Já no que concerne à recepção do roteiro de autoestudo pelos alunos, as enunciações nos permitiram a identificação de um material multifacetado, que se manifesta como "mediador da aprendizagem", como "fonte de conteúdo", como "marcador temporal" e, inclusive, como "exemplo de prática docente". Os dados, em linhas gerais, apontam que, independentemente do aspecto destacado, temos em todas as respostas um ponto assonante: referências à imprescindibilidade do recurso, dado o contexto do ensino remoto, e ao seu caráter norteador - essência fundadora do gênero.

Adicionalmente, como mencionado na apresentação dos aspectos metodológicos, no processo de coleta de dados, foi solicitada aos alunos a apresentação de possíveis sugestões para a melhoria do material. Assim, alguns deles, ao preencherem um item opcional do formulário aplicado, fizeram os seguintes apontamentos:

(23) "Professor, você está fazendo um excelente trabalho, não só com os roteiros, mas com todo o material disponibilizado na plataforma. Obrigada!"

(24) "Parabéns pela dedicação com os roteiros. São ótimos."

(25) "Estou muito satisfeita com os roteiros."

(26) "Os roteiros estão bem elaborados."

(27) "Para mim, eles estão ótimos."

(28) "Nenhuma sugestão."

(29) "Está ótimo!"

Os enunciados de (23) a (29) corroboram a avaliação positiva depreendida nas análises anteriores, além de validar uma prática passível de replicação em outros contextos. A validação da eficácia do roteiro de autoestudo pode, ainda, ser sintetizada pela adjetivação recorrente do recurso, sintetizada na nuvem de palavras da Figura 3, a seguir, a partir de dados coletados diretamente das enunciações dos alunos:

Figura 3 - Adjetivações atribuídas ao roteiro de autoestudo pelos alunos.

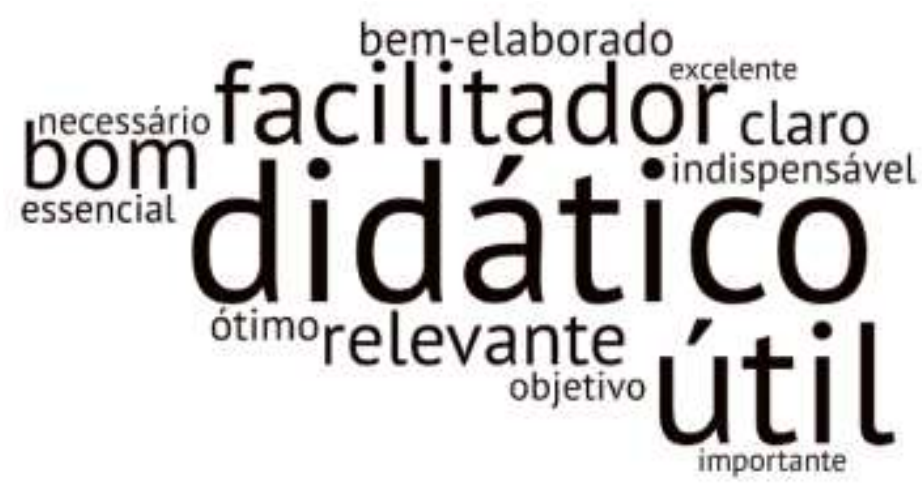

Fonte: Autores.

Em linhas gerais, portanto, os resultados apontam para o estabelecimento do roteiro de autoestudo como uma prática eficaz, que, no ensino remoto, permite ao aluno um diálogo mais próximo com o professor e, ao mesmo tempo, com o conteúdo.

Diante dessas considerações, esperamos que o percurso reflexivo aqui apresentado suscite novas discussões, como eixos norteadores de outros trabalhos e pesquisas sobre: (i) os recursos mobilizados na comunicação didática em diferentes 
modalidades de ensino, em especial aquelas em que os processos são mediados pelas tecnologias digitais; (ii) a adoção do gênero "roteiro de autoestudo" como um integrante das práticas de ensino e aprendizagem no contexto do Ensino Remoto Emergencial e, paralelamente, da Educação a Distância; e, por fim, (iii) as relações interacionais que se estabelecem entre alunos e professores no meio acadêmico.

\section{Agradecimentos}

À FUNADESP - Fundação Nacional de Desenvolvimento do Ensino Superior Particular, pelo apoio financeiro destinado à pesquisa.

\section{Referências}

Araújo, D. L. (2017). Enunciado e atividades e tarefas escolares: modos de fazer. Parábola.

Aulete, C. (2008). Dicionário contemporâneo da língua portuguesa. (2a ed.), Lexicon.

Bacich, L. (2018). Formação continuada de professores para o uso de metodologias ativas. In L. Bacich, J. M. Moran (Coord.). Metodologias ativas para uma educação inovadora: uma abordagem teórico-prática (pp. 129-152). Porto Alegre: Penso.

Bakhtin, M. (2010). Estética da criação verbal. Trad. Maria Ermantina Galvão G. Pereira. (5a ed.), Martins Fontes.

Buckingham, D. (2010). Cultura digital, educação midiática e o lugar da escolarização. Educação e Realidade, 35(3), $37-58$.

Carneiro, L. A., Rodrigues, W., França, G., \& Prata, D. (2020). Uso de tecnologias no ensino superior público brasileiro em tempos de pandemia COVID-19. Research, Society and Development, 9(8), 1-18.

Carvalho, F. V. L. (2020). A educação em quarentena: oportunidade de mudanças na direção de uma maior interdisciplinaridade. Pedagogia em Ação, 13(1), 193-204.

Carvalho, E. M. S., \& Araújo, G. C. (2020). Ensino remoto, saberes e formação docente: uma reflexão necessária. Revista Cocar, 14(30), 1-19.

Das, A., Lam, T. K., Thomas, S., Richardson, J., Kam, B. H., Lau, K. H., \& Nkhoma, M. Z. (2019). Flipped classroom pedagogy. Using pre-class videos in an undergraduate business information systems management course. Education \& Training, 61(6), 756-774.

Dionísio, A. P. (2011). Gêneros multimodais e multiletramento. Nova Fronteira.

Dionísio, A. P., \& Vasconcelos, L. J. (2013). Multimodalidade, gênero textual e leitura. In C. Bunzen, M. Mendonça (Coord.). Múltiplas linguagens para o Ensino Médio (pp. 19-42). São Paulo: Parábola.

Dudeney, G., Hockly, N., \& Pegrum, M. (2016). Letramentos digitais. Trad. Marcos Marciolino. Parábola.

Fonteque, V. S., Bueno, S. R., Giordani, A. T., Ancelmo, L. A., Nantes. E. A. S., \& Reinaldi, M. A. A. (2021). Ensino remoto em tempos de pandemia: percepções de alunos do Ensino Fundamental Anos Finais. In L. A. F. A. P. Mourad, F. I. J. Cunha, W. J. Jorge (Coord.). Ensino Remoto Emergencial: experiência de docentes na pandemia (pp. 214-231). Maringá: Uniedusul.

Freire, P. (1979). Extensão ou comunicação? Paz e Terra.

Guerra Junior, A. L. (2021). Metodologia do Ensino de Português II: roteiro das aulas 13 e 14 (1º bimestre). Apucarana: Unespar.

Houaiss, A. (2009). Dicionário Houaiss da língua portuguesa. Objetiva.

Kress, G., \& Van Leeuwen, T. (1996). Reading images: the grammar of visual design. Routledge.

Lévy, P. (1999). Cibercultura. Ed. 34.

Marconi, M. A., \& Lakatos, E. M. (2003). Fundamentos de metodologia científica. (5a ed.), Atlas.

Meirieu, P. (1998). Aprender... sim, mas como? Artmed.

Moran, J. (2018). Metodologias ativas para uma aprendizagem mais profunda. In L. Bacich, J. M. Moran (Coord.). Metodologias ativas para uma educação inovadora: uma abordagem teórico-prática (pp. 1-25). Penso.

Paiva, V. L. M. O. (2019). Manual de pesquisa em estudos linguísticos. Parábola.

Price, S. (2017). Script development and academic research. Journal of Screenwriting, 8(3), 319-333.

Ribeiro, A. E. F. (2020). Letramento digital e ensino remoto: reflexões sobre práticas. Debates em Educação, 12(2), 446-460. 
Research, Society and Development, v. 10, n. 13, e160101320891, 2021

(CC BY 4.0) | ISSN 2525-3409 | DOI: http://dx.doi.org/10.33448/rsd-v10i13.20891

Rojo, R. (2012). Pedagogia dos multiletramentos. In R. Rojo, E. Moura (Coord.). Multiletramentos na escola (pp. 11-31). Parábola.

Sant'anna, I. M., \& Sant'anna, V. (2004). Recursos educacionais para o ensino: quando e por quê?? Vozes.

Souza, S. E. (2007). O uso de recursos didáticos no ensino escolar. In I Encontro de Pesquisa em Educação, IV Jornada de Prática de Ensino, XIII Semana de Pedagogia da UEM: "Infância e Práticas Educativas". UEM.

Street, B. V. (2014). Letramentos sociais: abordagens críticas do letramento no desenvolvimento, na etnografia e na educação. Trad. Marcos Bagno.

Parábola.

Tardif, M. (2014). Saberes docentes e formação profissional. (17a ed.), Vozes.

Vygotsky, L. S. (1999). Pensamento e linguagem. Martins Fontes.

Yin, R. K. (2001). Estudo de caso: planejamento e métodos. Trad. Daniel Grassi. (2a ed.), Bookman. 